\title{
Synthesis of Polymer Electrolyte Membrane based on Acid-Base Complex Pair and Its Characteristics
}

\author{
Irfan Gustian ${ }^{1}$, Sevim Ünugur Çelik ${ }^{2}$, Ahmad Zainuddin ${ }^{3}$, Wawang Suratno ${ }^{3}$, \\ Ayhan Bozkurt ${ }^{2} \&$ Rustam Efendi Siregar ${ }^{4}$ \\ ${ }^{1}$ Department of Chemistry, Faculty of Mathematics and Natural Sciences \\ Universitas Bengkulu, Jalan Raya Kandang Limun, Bengkulu 38371, Indonesia \\ ${ }^{2}$ Department of Chemistry, Fatih University, 34500 Büyükçekmece, Istanbul, Turkey \\ ${ }^{3}$ Department of Chemistry, Universitas Padjadjaran, \\ Jalan Raya Jatinangor Km. 21, Jatinangor 40600, Indonesia. \\ ${ }^{4}$ Department of Physics, Universitas Padjadjaran, \\ Jalan Raya Jatinangor Km. 21, Jatinangor 40600, Indonesia \\ Email: unibfan@yahoo.com
}

\begin{abstract}
In this work, acid-base complex pair polymer electrolyte membranes on sulfonated polysulfone with $1 \mathrm{H}$-benzotriazole were investigated. Polysulfone was sulfonated in 1,2-dichloroethane using the homogeneous method with trimethylsilyl chlorosulfonate as sulfonating agent. The monomer mole ratio between polysulfone and trimethysilyl chlorosulfonate was 1:1.5. The sulfonated polysulfone was added with $1 \mathrm{H}$-benzotriazole at mole ratios of $\mathrm{x}=0.5$ and $\mathrm{x}=1$. The proton transfer from $1 \mathrm{H}$-benzotriazole to the sulfonated polysulfone was measured using FTIR. Thermo-gravimetry analysis showed that the samples were thermally stable up to approximately $250^{\circ} \mathrm{C}$ and the maximum proton conductivity was found to be $3.34 \times 10^{-4} \mathrm{~S} \mathrm{~cm}^{-1}$ at $150^{\circ} \mathrm{C}$.
\end{abstract}

Keywords: Sulfonated polysulfone; 1H-benzotriazole; acid-base complex pair; homogeneous; polymer electrolyte membranes; proton conductivity.

\section{$1 \quad$ Introduction}

Proton exchange membranes (PEMs) are commonly used to drive conductivity. In order to achieve acceptable levels of proton conductivity, conventional PEMs need water, which is unsuitable for high-temperature operation of fuel cells. To overcome this problem, one needs to use pure polymer membranes for anhydrous proton conduction. However, despite their high thermal and chemical stability, some of these materials suffer from complex external humidification and high material cost $[1,2]$.

There are many thermoplastic polymers that can be used for polymer electrolyte membranes. It has been reported that polysulfone was considered more interesting because of its low cost, commercial availability and ease to be processed [3-5]. Polysulfone, as shown in Figure 1, can be synthesized through

Received July $8^{\text {th }}, 2013,1^{\text {st }}$ Revision October $12^{\text {th }}, 2013$, Accepted for publication March $12^{\text {th }}, 2014$.

Copyright (c) 2014 Published by ITB Journal Publisher, ISSN: 2337-5760, DOI: 10.5614/j.math.fund.sci.2014.46.1.5 
condensation polymerization between diphenol and 4,4-dichloro-diphenyl sulfone. To achieve good anhydrous proton conductivity, polysulfone must be highly sulfonated, because a sulfone compound as a side chain can easily form a hydrogen bond with a nitrogen-containing heterocycle compound.

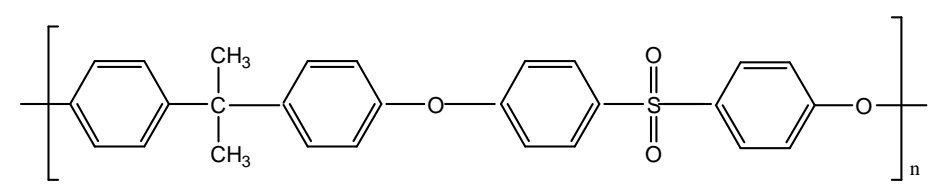

Figure 1 Polysulfone.

In order to obtain highly sulfonated polysulfone, the polysulfone polymer has to be dissolved in a solvent, and then treated with a sulfonation agent with a given mole ratio. It has been reported by Lufrano, et al. [4] that using chloroform as the solvent at $25^{\circ} \mathrm{C}$ and a mole ratio of $1: 1.5$ resulted in a maximum sulfonation degree of $77 \%$. However, Sheng-Li, et al. [6] used1,2-dichloroethane and the same sulfonation agent with mole ratios of $1: 1.43$ and 1:2.86 at room temperature, which resulted in sulfonation degrees of $87 \%$ and $127 \%$, respectively.

In the last decade, nitrogen-containing heterocycle compounds such as imidazole [7], benzimidazole [8,9] and triazole derivatives [10-13] have been reported to be promising protonic charge carriers in anhydrous state. Proton conduction in these systems may occur through a mechanism where protons are transferred by a hydrogen-bond breaking and forming process without the involvement of water acting as a carrier [7,14,15].

In this work we synthesised samples of polysulfone membranes with a higher degree of sulfonation in order to increase the proton conductivity at higher temperatures. The synthesis of sulfonated polysulfone was performed using 1,2dichloroethane as the solvent. The composite polymer membranes of sulfonated polysulfone were prepared by adding $1 \mathrm{H}$-benzotriazol. The composite polymer membranes were evaluated in terms of sulfonation degree,thermal stabilities, phase transition, and proton conductivities.

\section{Experimental}

\subsection{Materials}

Commercial polysulfone (PSU) and trimethylsilyl chlorosulfonate (TMSCS) were purchased from Aldrich; dimethylformamide,1,2-dichloroethane from 
Merck; methanol from Sigma-Aldrich;and 1H-benzotriazole (BTri) from Alfa A.

\subsection{Synthesis of Sulfonated Polysulfone}

The sulfonation process was similar to the method used by Sheng-Li, et al. [6]. PSU was dissolved in 1,2-dichloroethane at a temperature of $25^{\circ} \mathrm{C}$ under a stream of nitrogen gas. The time required to dissolve polysulfone in 1,2dichloroethane was 5 hours. This was long enough because 1,2-dichloroethane has a high dipole moment (1.86 D) and dielectric constant (10.36).

TMSCS was added as the sulfonation agent into the solution at room temperature. The amount of TMSCS was determined based on the mole ratio between the PSU and the TMSCS it self. According to Sheng-Li, et al. [6], mole ratios of 1:1.43 and 1:2.86 with a reaction time of 36 hours at room temperature resulted in sulfonation degrees of $87 \%$ and $127 \%$, respectively. Based on these results, we chose a mole ratio of 1:1.5. The volume of the solvent used was $100 \%$ of the weight of the polysulfone.

The sulfonation was stopped by adding methanol to obtain sulfonated polysulfone (SPSU). The final sulfonated products were washed with methanol and rinsed several times with distillate water. For complete removal of the solvents, they were evaporated at a pressure of $1 \mathrm{~atm}$ and then dried in a vacuum oven at a pressure of $400 \mathrm{~mm} \mathrm{Hg}$ and a temperature $55^{\circ} \mathrm{C}$. The degree of sulfonation was determined by titration using $0.01 \mathrm{~N} \mathrm{NaOH}$ that was standardized.

\subsection{Preparation of Composite Membranes}

Preparation of the membranes was performed by mixing BTri and SPSU in dimethylformamide. The amounts of SPSU and BTri were determined using the stoichiometric ratios of moles; the ratios were 1:0.5 and 1:1. In order to obtain a homogeneous polymer solution, the mixture was stirred for 12 hours at room temperature. The mixture was cast on a Teflon container and evaporated slowly at a temperature of $50^{\circ} \mathrm{C}$ for 24 hours and then evaporated in a vacuum oven at a pressure of $200 \mathrm{mmHg}$ and a temperature of $50^{\circ} \mathrm{C}$ to get rid of the solvent residue in the membrane.

\subsection{Characterizations}

The FTIR spectra were recorded on a Bruker Alpha-P with Attenuated Total Reflectance in a range of 4000-400 $\mathrm{cm}^{-1}$. The thermal stabilities of the polymer electrolytes were examined by TG analyses using a Perkin Elmer STA 6000. The samples $(\sim 10 \mathrm{mg})$ were heated from room temperature to $700^{\circ} \mathrm{C}$ under $\mathrm{N}_{2}$ 
atmosphere at a scanning rate of $10^{\circ} \mathrm{C} / \mathrm{min}$. DSC measurements were carried out using a Perkin Elmer JADE DSC under nitrogen atmosphere; heatingcooling curves were recorded at a rate of $10^{\circ} \mathrm{C} / \mathrm{min}$. The proton conductivity studies of the samples were performed using a Novocontrol dielectricimpedance analyzer. The films were sandwiched between gold blocking electrodes and the conductivities were measured in a frequency range of $0.1 \mathrm{~Hz}$ to $1 \mathrm{MHz}$ in $10^{\circ} \mathrm{C}$ intervals. The temperature between -100 and $250{ }^{\circ} \mathrm{C}$ was controlled using a Novocontrol cryosystem.

\section{$3 \quad$ Results and Discussion}

\subsection{Sulfonation}

The degree of sulfonation as a function of reaction time is depicted in Figure 2. We see that the sulfonation degree increased exponentially with the increase of the reaction time. To prevent excessive sulfonation, the longest reaction time in this work was 36 hours. The sulfonation degree with this reaction time was $134 \%$ higher than the result of Sheng-Li, et al. [6] with mole ratio 1:2.86. The resulted SPSU was not dissolved in chloform and 1,2-dichloroethane but soluble in dimethyl formamide.

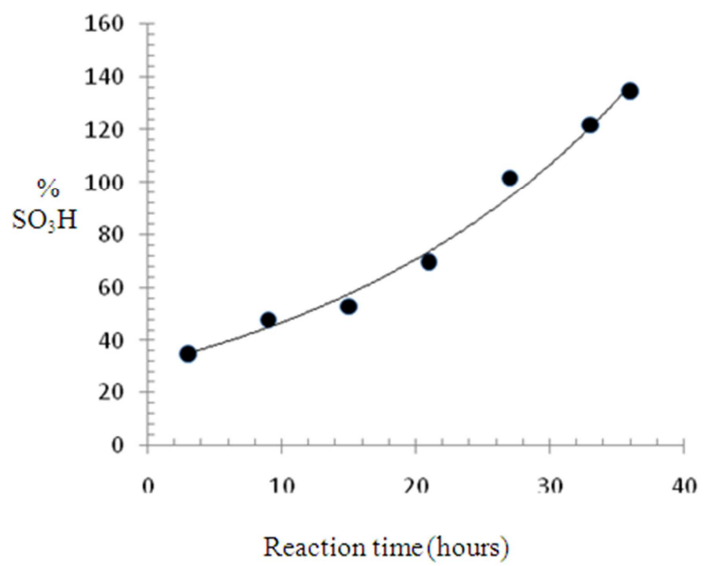

Figure 2 Sulfonation degrees (\%) as a function of reaction time.

\subsection{FTIR Studies}

Figure 3 shows the FTIR spectra of polysulfone, synthesized sulfonated polysulfone, and BTri. From the peaks at $690 \mathrm{~cm}^{-1}, 1041 \mathrm{~cm}^{-1}, 1103 \mathrm{~cm}^{-1}, 1149$ $\mathrm{cm}^{-1}, 1238 \mathrm{~cm}^{-1}, 1485 \mathrm{~cm}^{-1}, 2950 \mathrm{~cm}^{-1}, 3110 \mathrm{~cm}^{-1}$, and $3500 \mathrm{~cm}^{-1}$, it was confirmed that the peaks were attributable to the presence of $\mathrm{C}-\mathrm{S}, \mathrm{SO}_{3}, \mathrm{C}-\mathrm{O}, \mathrm{R}-$ 
$\mathrm{SO}_{2}-\mathrm{R}, \mathrm{C}-\mathrm{O}, \mathrm{C}=\mathrm{C}$ (aromatic), $\mathrm{CH}$ (aliphatic), $\mathrm{CH}$ (aromatic), and $\mathrm{OH}$ stretching bonds respectively from sulfonated polysulfone [16]. This is different from the spectrum of polysulfone. In this spectrum there are no peaks at $3500 \mathrm{~cm}^{-1}$ and near $1041 \mathrm{~cm}^{-1}$, which can be attributed to $-\mathrm{OH}$ and asymmetric $\mathrm{O}=\mathrm{S}=\mathrm{O}$ stretching vibration of $-\mathrm{SO}_{3}$ groups respectively. The SPSU compound is shown in Figure 4 [6].The functional groups and wave numbers of polysulfone (PSU) and sulfonated polysulfone (SPSU) are shown in Table 1.

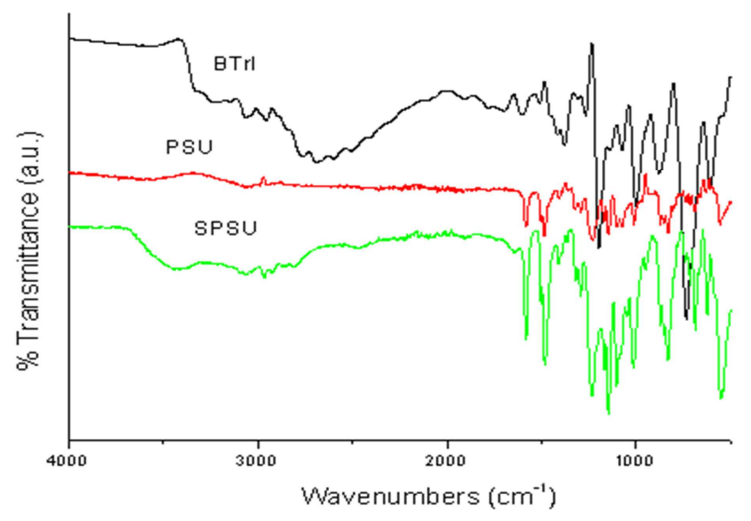

Figure 3 FTIR spectra of polysulfone (PSU), synthesized sulfonated polysulfone (SPSU), and 1H-Benzotriazole (BTri).

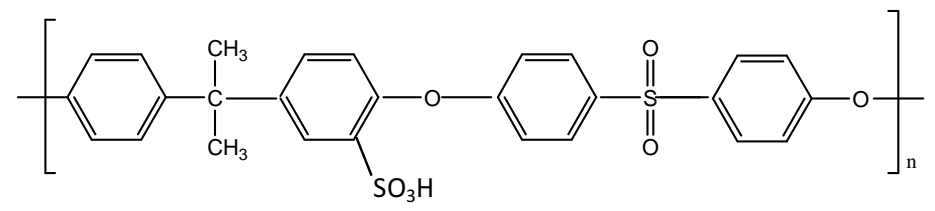

Figure 4 Sulfonated polysulfone [6].

Table 1 Functional groups and wave numbers of polysulfone (PSU) and sulfonated polysulfone (SPSU).

\begin{tabular}{|c|c|c|c|}
\hline $\begin{array}{c}\text { Functional groups of } \\
\text { polysulfone }\end{array}$ & $\begin{array}{c}\text { Wave } \\
\text { numbers } \\
\left(\mathrm{cm}^{-1}\right)\end{array}$ & $\begin{array}{l}\text { Functional groups of } \\
\text { sulfonated polysulfone }\end{array}$ & $\begin{array}{c}\text { Wave } \\
\text { numbers } \\
\left(\mathrm{cm}^{-1}\right)\end{array}$ \\
\hline Stretching vibration C-S & 690 & Stretchingvibration C-S & 690 \\
\hline Stretching symmetry $-\mathrm{SO}_{3^{-}}$ & - & Stretching symmetry $-\mathrm{SO}_{3}-$ & $1310-1200$ \\
\hline Stretching vibration $-\mathrm{SO}_{2-}$ & $1360-1300$ & Stretching vibration $-\mathrm{SO}_{2-}$ & $1360-1300$ \\
\hline Stretching vibration $\mathrm{C}-\mathrm{O}-\mathrm{C}$ & $1300-1175$ & Stretching vibration $\mathrm{C}-\mathrm{O}-\mathrm{C}$ & $1300-1175$ \\
\hline Stretching vibration $\mathrm{C}=\mathrm{C}$ & $1700-1500$ & Stretching vibration $\mathrm{C}=\mathrm{C}$ & $1700-1500$ \\
\hline $\mathrm{CH}$ (aliphatic) & $3400-2700$ & $\mathrm{CH}$ (aliphatic) & $3400-2700$ \\
\hline $\mathrm{CH}$ (aromatic) & 3110 & $\mathrm{CH}$ (aromatic) & 3110 \\
\hline Stretching vibration $\mathrm{O}-\mathrm{H}$ & - & Stretching vibration $\mathrm{O}-\mathrm{H}$ & $3700-2900$ \\
\hline
\end{tabular}


The FTIR spectrum of BTri in Figure 3 shows C-N stretching at around 1430 $1650 \mathrm{~cm}^{-1}$ and a peak at $1270 \mathrm{~cm}^{-1}$ that are attributable to N-N stretching. The peaks at $670-1225 \mathrm{~cm}^{-1}$ are attributable to $\mathrm{C}-\mathrm{H}$, the peak at $1629 \mathrm{~cm}^{-1}$ is attributable to $\mathrm{C}=\mathrm{C}$ stretching bands, and the peak around $3380 \mathrm{~cm}^{-1}$ is attributable to $\mathrm{N}-\mathrm{H}$ stretching.

Figure 5 shows the FTIR spectra acid-base complex pair sulfonated polysulfone and BTri for mole ratios 1:0.5 (SPSBTri0.5) and 1:1 (SPSBTri1), respectively.

The band between 3000 and $2000 \mathrm{~cm}^{-1}$ can be attributed to the possibility of the formation and interaction between BTri and SPSU, which were supported in the $1800-900 \mathrm{~cm}^{-1}$ region and peaked near $1100 \mathrm{~cm}^{-1}$ and $979 \mathrm{~cm}^{-1}$. A similar study of the interaction acid-base complex pair in proton conducting composite membranes based on poly(1-vinyl-1,2,4-triazole) and nitrilotri(methyl triphosphonicacid) has been reported by Gustian, et al. [12]. Acid-base complex pair sulfonated polysulfone and Btri are shown in Figure 6. Moreover, previous studies of the interaction acid-base complex pair between poly $(2,5$ benzimidazole) and poly(styrene sulfonic acid) have been reported by Acar, et al. [9]; more details are shown in Table 2.

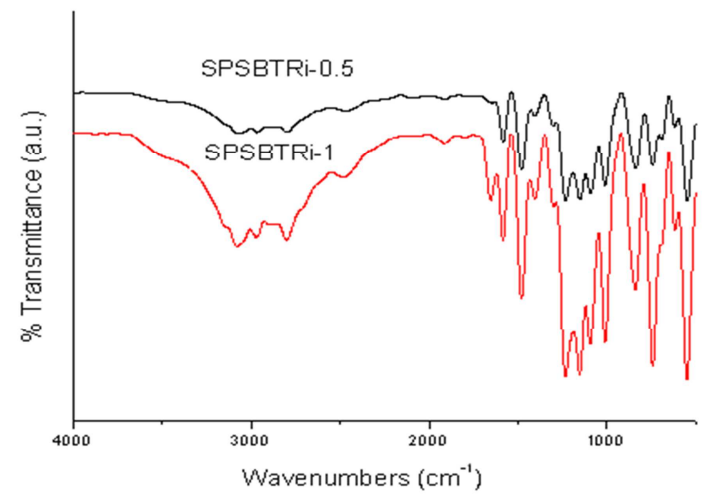

Figure 5 FTIR spectra of the membranes of SPSBTri0.5 and SPSBTri1.

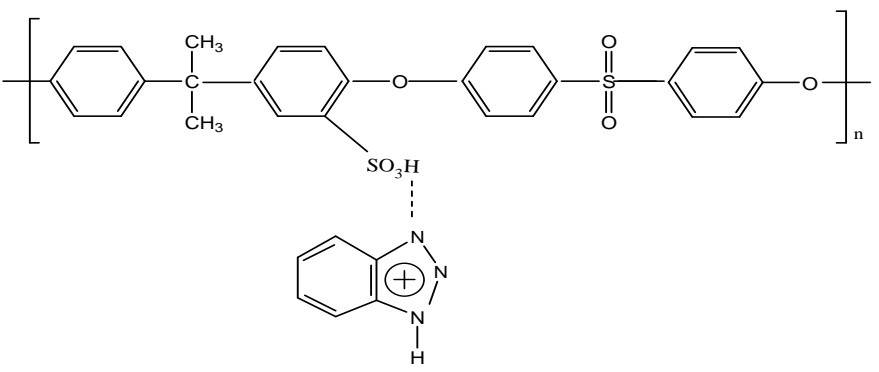

Figure 6 Acid-base complex pair sulfonated polysulfone and Btri. 
Table 2 Functional groups and wave numbers of benzotriazole (Btri) and membranes of SPSBTri.

\begin{tabular}{|c|c|c|c|}
\hline $\begin{array}{l}\text { Functional Groups of } \\
\text { Benzotriazole (Btri) }\end{array}$ & $\begin{array}{c}\text { Wave } \\
\text { Numbers } \\
\left(\mathrm{cm}^{-1}\right)\end{array}$ & $\begin{array}{l}\text { Functional Groups of } \\
\text { Membranes of SPSBTri }\end{array}$ & $\begin{array}{c}\text { Wave } \\
\text { Numbers } \\
\left(\mathrm{cm}^{-1}\right)\end{array}$ \\
\hline Stretching vibration N-H & 3380 & Stretching vibrationN-H & 3380 \\
\hline $\begin{array}{l}\text { Interactionacid-base } \\
\text { complex pair }\end{array}$ & - & $\begin{array}{l}\text { Interactionacid-base complex } \\
\text { pair }\end{array}$ & $3000-2000$ \\
\hline Stretching vibrationC $=\mathrm{N}$ & $1700-1570$ & Stretching vibration $\mathrm{C}=\mathrm{N}$ & $1700-1570$ \\
\hline Stretching vibrationC $=\mathrm{C}$ & 1629 & Stretching vibrationC $=\mathrm{C}$ & 1629 \\
\hline Stretching vibration $-\mathrm{SO}_{2-}^{-}$ & - & Stretching vibration $-\mathrm{SO}_{2^{-}}$ & $1360-1300$ \\
\hline Stretching symmetr- $\mathrm{SO}_{3}-$ & - & Stretching symmetry $-\mathrm{SO}_{3}-$ & $1310-1200$ \\
\hline Stretching vibrationN-N & 1270 & Stretching vibrationN-N & 1270 \\
\hline $\begin{array}{l}\text { Absorption acid-base } \\
\text { complex pair }\end{array}$ & - & $\begin{array}{l}\text { Absorption acid-base } \\
\text { complex pair }\end{array}$ & $1100-979$ \\
\hline Bending vibration $\mathrm{C}-\mathrm{H}$ & $750-650$ & Bending vibration $\mathrm{C}-\mathrm{H}$ & $750-650$ \\
\hline
\end{tabular}

\subsection{Thermal Analysis}

Figure 7 shows the thermograms of PSU polymer, SPSU, SPSBTri0.5 and SPSBTri1. The PSU polymer has very high stability, its glass transition temperature is about $185^{\circ} \mathrm{C}$, and degradation to appear at $500^{\circ} \mathrm{C}$ corresponding to the degradation of the polymer backbone; this pattern is similar to previous studies [17]. The figure also shows the first weight loss of SPSBTri1 at around $100^{\circ} \mathrm{C}$, SPSBTri0.5 and SPSU at around $250^{\circ} \mathrm{C}$. The weight loss is related to the loss of water that is physically adsorbed in the samples. Both of SPSU and polymer membrane electrolytes were degraded at $200^{\circ} \mathrm{C}$.

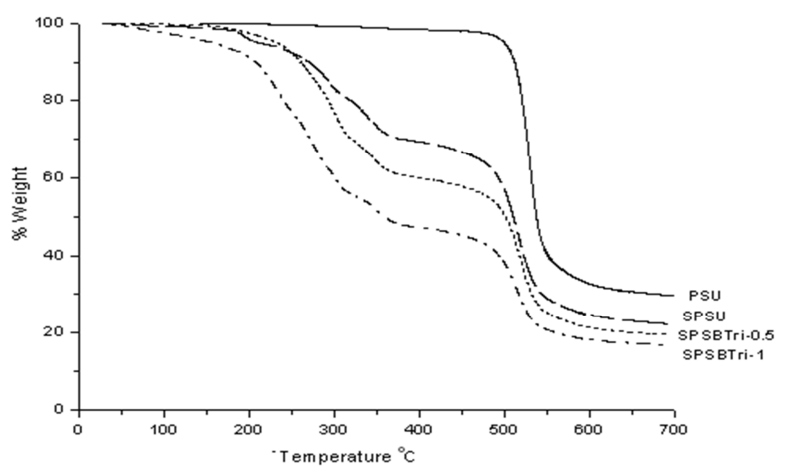

Figure 7 Thermograms of polysulfone polymer(PSU), membrane of sulfonated polysulfone (SPSU), membranes of SPSBTri0.5 and SPSBTri1. 
The BTri effects can be seen clearly at $200^{\circ} \mathrm{C}$; the membrane having a higher mole ratio is easier to be degraded. At temperatures above $200^{\circ} \mathrm{C}$ the weight of the membranes declines continuously until $500^{\circ} \mathrm{C}$. The weight loss of the membrane is due to the thermal decomposition of side groups and the polymer main chain.

The thermal stability of sulfonated polysulfon membrane was investigated using a thermogravimetric analysis/mass spectrometer. The first weight loss at around $100^{\circ} \mathrm{C}$ is caused by evaporation of water molecules bound in hydrophilic sulfonated polysulfon membrane. The secondary weight loss between 200 and $400^{\circ} \mathrm{C}$ is mainly due to the thermally activated decomposition of sulfonic acid groups in the polymer chain, which is confirmed by the evolution of SO and $\mathrm{SO}_{2}$ gas detected in the mass spectra [18]. All of the samples were thermally stable in the temperature range of proton conductivity measurements. In the DSC measurements, we found the glass transition temperature $T g$ of SPSU to be $65.5^{\circ} \mathrm{C}$, while the glass transition temperature for SPSBTri0.5 and SPSBTri1 was found to be $64^{\circ} \mathrm{C}$ and $62^{\circ} \mathrm{C}$, respectively.

\subsection{Conductivity Measurements}

The frequency-dependent AC conductivities, $\sigma_{\mathrm{ac}}(\omega)$, of the polymer electrolyte membranes were measured at several temperatures using the following equation:

$$
\sigma^{\prime}(\omega)=\sigma_{a c}(\omega)=\varepsilon^{\prime \prime}(\omega) \omega \varepsilon_{0}
$$

where $\sigma^{\prime}(\omega)$ is the real part of conductivity, $\omega=2 \pi f$ is the angular frequency, $\varepsilon_{0}$ is the vacuum permittivity, and $\varepsilon^{\prime \prime}$ is the imaginary part of complex dielectric permittivity. The proton conductivities of the anhydrous complex polymer electrolytes were measured at several temperatures between 20 and $150^{\circ} \mathrm{C}$.

Figure 8 shows the AC conductivities of membrane SPSBTri1 versus the log frequency at several temperatures. Each curve shows two regions that are typical for ion conducting polymers. A low frequency region at low temperatures is related to conduction processes in the bulk of samples. This region shifts to higher frequencies with increasing temperature. The irregularities at the low frequency side at higher temperatures are caused by electrode polarization due to blocking effect of the electrodes. From curve the AC conductivity of sulfonated polysulfone-BTril versus log frequency at measurements $90^{\circ} \mathrm{C}$, shows the change a transition. Where in general, below $100^{\circ} \mathrm{C}$ the proton transport mechanism that occurs is vehicle mechanism. The direct current (DC) conductivities of the samples are generated from the plateau regions by extrapolating to zero frequency. DC conductivity strongly depends on the temperature and the mole ratio of BTri. From the measurements at $150^{\circ} \mathrm{C}$ 
we obtained a conductivity of $2.52 \times 10^{-4} \mathrm{~S} \mathrm{~cm}^{-1}$ for SPSBTri0.5 and $3.34 \times 10^{-4}$ $\mathrm{S} \mathrm{cm}^{-1}$ for SPSBTri1.

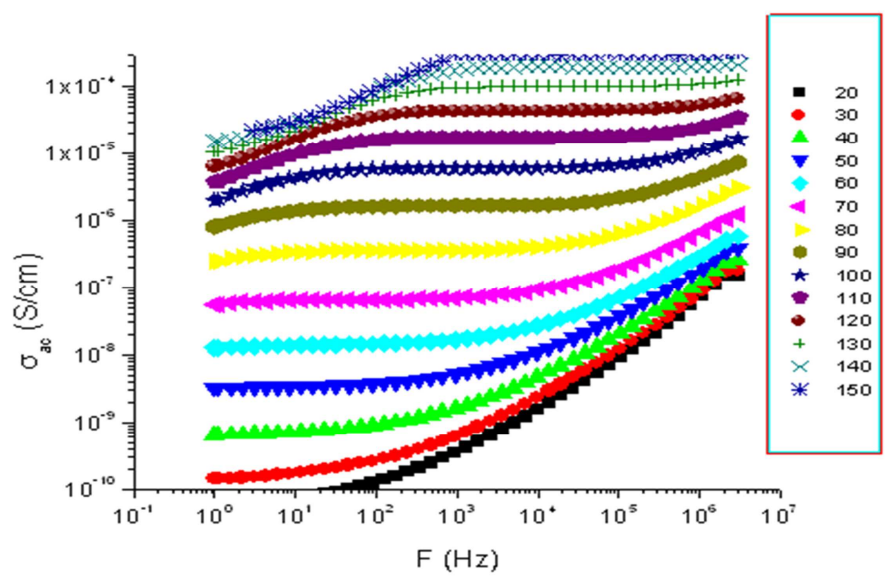

Figure 8 The AC conductivity of sulfonated polysulfone-BTri1 versus log frequency at several temperatures.

From Figure 8 we obtained the DC conductivity as a function of reciprocal temperature, as depicted in Figure 9. As shown in the figure, we have been made a linear fitting of two groups of data, i.e. lower and higher temperature data. The intersection of the two lines is at $1000 / T\left(\mathrm{~K}^{-1}\right)=2.975$ or $T=63^{\circ} \mathrm{C}$, which is close to glass temperature $T g$ obtained by DSC. At the glass transition temperature, the membranes still exhibit thermal stability up to $150^{\circ} \mathrm{C}$, which is also shown by the conductivity measurements.

Using Arrhenius equation

$$
\sigma_{D C}(T)=A \exp \left(-\frac{E}{k_{B} T}\right)
$$

where $k_{B}$ is the Boltzmann constant and $E$ is the activation energy, we obtain $E=1.83 \mathrm{eV}$ for $T \leq 63^{\circ} \mathrm{C}$ and $E=1.25 \mathrm{eV}$ for $T \geq 63^{\circ} \mathrm{C}$. This means that the activation energy of the protons decreased with increasing temperature.

It was found that the membrane with a higher mole ratio of BTri has a higher conductivity. In this case, the proposed model of proton transport occurs via structural diffusion of proton conductivity is mainly controlled by the proton transport. This mechanism is known as the 'Grotthus mechanism', includes the proton hopping from one protonated site to the next non-protonated site, protons can be transferred from a protonated BTri molecule to a neighbor non- 
protonated BTri molecule. Therefore, at higher addition of Btri, a proton can be transferred rapidly to a neighboring molecule with small activation energy, especially at higher temperatures. The transport of the proton in the membrane follow Grotthuss diffusion, can be explained by BTri replace water to promote proton conductivity of materials at temperatures above $100^{\circ} \mathrm{C}$.

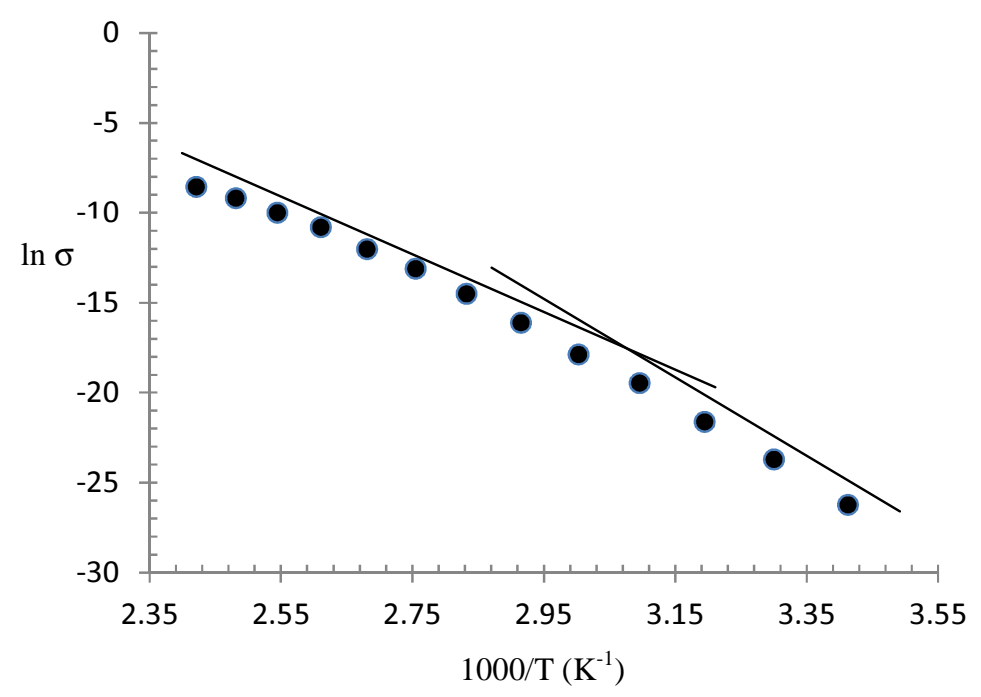

Figure 9 Conductivity as a function of reciprocal temperature.

\section{Conclusions}

We have successfully synthesized sulfonated polysulfone polymers with a sulfonation degree of $134 \%$ using 1,2-dichloroetana as solvent and trimethysilyl chlorosulfonate as sulfonating agent with a mole ratio of 1:1.5. The polymer electrolyte membranes were prepared by mixing the sulfonated polysulfone polymers with $1 \mathrm{H}$-Benzotriazole with mole ratios $1: 0.5$ and $1: 1$ in dimethylformamide. The FTIR spectra of the membranes exhibited the presence of interaction $1 \mathrm{H}$-Benzotriazole and sulfonated polysulfone polymer. DSC measurements showed that the $T g$ temperature of the polymer electrolyte membrane with mole ratio $1: 1$ was $62^{\circ} \mathrm{C}$. The temperature dependence of the proton conductivity showed that the activation energy at temperatures lower than $T g$ was $1.83 \mathrm{eV}$, while the activation energy at temperatures higher than $T g$ was $1.25 \mathrm{eV}$. The proton conductivity of the polymer electrolyte membrane was found to be $3.34 \times 10^{-4} \mathrm{~S} \mathrm{~cm}^{-1}$ at $150^{\circ} \mathrm{C}$. 


\section{Acknowledgements}

We would like to thank the Department of Chemistry, Fatih University, Istanbul, Turkey for recording the FTIR, TG, DSC, and proton conductivity. The authors are also grateful to the Department of Chemistry and the Department of Physics, Universitas Padjadjaran, Indonesia and the Department of Chemistry, Universitas Bengkulu, Indonesia.

\section{References}

[1] Kalapos, T.L., Decker, B., Every, H.A., Ghassemi, H. \& Zawodzinski, T.A., Thermal Studies of the State of Water in Proton Conducting Fuel Cell Membranes, J. Power Sources, 172, pp. 14-19, 2007.

[2] Hickner, M.A., Ghassemi, H., Kim, Y.S., Einsla, B.R. \& McGrath, J.E., Alternative Polymer Systems for Proton Exchange Membranes(PEMs), Chem. Rev., 104, pp. 587-4612, 2004.

[3] Lufrano, F., Squadrito, G., Patti, A. \& Passalacqua, E., Sulfonated Polysulfone as Promising Membrans forPolymer Electrolyte Fuel Cells, Journal of Applied Polymer Science, 77, pp. 1250-1257,2000.

[4] Lufrano, F., Squadrito, G., Patti, A. \& Passalacqua, E., Sulfonated Polysulfone Ionomer Membrans for Fuel Cells, Solid State Ionics, 145, pp. 47-51, 2001.

[5] Lufrano, F., Baglio, V., Staiti, P., Arico, A.S. \& Antonucci, V., Development and Characterization of Sulfonated Polysulfone Membranes for Direct Methanol Fuel Cells, Desalination, 199, pp. 283-285, 2006.

[6] Sheng-Li, C., Bocarsly, A.B. \& Benjiger, J., Nafion-layered Sulfonated Polysulfone Fuel Cell Membranes, Journal of Power Sources, 152, pp. 27-33, 2005.

[7] Bozkurt, A., Meyer, W.H. \& Wegner, G., Polyacrylic Acid (PAA)/ Imidazol-based Proton Conducting Polymer Electrolytes, Journal of Power Sources, 123, pp. 126-131, 2003.

[8] Fu, Y., Li, W. \& Manthiram, A., Sulfonated Polysulfone with 1,3-1HDibenzimidazole-Benzene Additive as a Membrane for Direct Methanol Fuel Cells, Journal of Membrane Science, 310, pp. 262-267, 2008.

[9] Acar, O., Sen, U., Bozkurt, A. \& Ata, A., Blend Membranes from Poly(2,5 benzimidazole) and Poly(styrene sulfonic acid) as ProtonConducting Polymer Electrolytes for Fuel Cells, J Mater Sci., 45, pp. 993-998, 2010.

[10] Aslan, A., Celik, S.U., Sen, U., Haser, R. \& Bozkurt, A., Intrinsically Proton-conducting Poly(1-vinyl-1,2,4-triazole)/Triflic Acid Blends, Electrochim Acta, 54, pp. 2957-2961, 2008. 
[11] Celik, S.U., Aslan, A. \& Bozkurt, A., Phosphoric Acid-doped poly(1vinyl-1,2,4-triazole) as Water-FreeProton Conducting Polymer Electrolytes, Solid State Ionics, 179, pp. 683-688, 2008.

[12] Gustian, I., Celik, S.U., Suratno, W. \& Bozkurt, A., Proton Conducting Composite Membranes based on Poly(1-vinyl-1,2,4-triazole) and Nitrilotri (methyl triphosphonic acid), Journal of Physics and Chemistry of Solids, 72, pp. 1377-1380, 2011.

[13] Li, S., Zhou, Z., Zhang, Y. \& Liu, M., 1H-1,2,4-Triazole: An Effective Solvent for Proton-Conducting Electrolytes, Chem. Mater., 17, pp. 58845886, 2005.

[14] Bozkurt, A. \& Meyer, W.H., Proton Conducting Blends of Poly(4vinylimidazole) with Phosphoric Acid, Solid State Ionics, 138, pp. 259265, 2001.

[15] Celik, S.U., \& Bozkurt, A., Proton Conduction Promoted by 1H-1,2,3Benzotriazole in Non-Humidified Polymer Membranes., Electrochimica Acta, 56, pp. 5961- 5965, 2011.

[16] Chennamsetty, R., Isabel E. \& Xinglong, X., Characterization of Commercial Membranes Modified via Ion Beam Irradiation, Desalination, 188, pp. 203-212, 2006.

[17] Lufrano, F., Baglio, V., Staiti, V.P., Arico, A.S. \& Antonucci, V., Polymer Electrolytes Based on Sulfonated Polysulfone for Direct Metanol Fuel Cells, Journal of Power Sources, 179, pp. 34-41, 2008.

[18] Bum, P.H., Shin, H.-S., Lee, Y.M. \& Rhim, J.-W., Annealing Effect of Sulfonated Polysulfone Ionomer Membrans on Proton Conductivity and Metanol Transport, Journal of Membrane Science, 247, pp. 103-110, 2005. 